\title{
Antibacterial activity of Alstonia angustifolia leaf extract against Staphyloccoccal and Bacilli.
}

\author{
Nurhidayah Ab Rahim ${ }^{1 *}$, Noorzafiza Zakaria ${ }^{1}$, Syarifah Masyitah Habib Dzulkarnain ${ }^{1}$, Nursyuhadah \\ Othman $^{2}$, Mahmood Ameen Abdulla ${ }^{3}$ \\ ${ }^{1}$ Faculty of Health Sciences, University Technology MARA, Pulau Pinang Branch (Bertam Campus), Malaysia \\ ${ }^{2}$ Faculty of Pharmacy, University Technology MARA, Pulau Pinang Branch (Bertam Campus), Malaysia \\ ${ }^{3}$ Faculty of Medicine, University of Malaya, Kuala Lumpur, Malaysia
}

\begin{abstract}
AIstonia angustifolia were applied in traditional medicine to cure malaria disease and remittent fever. The aim of this study is to evaluate the potential antibacterial properties of $\boldsymbol{A}$. angustifolia leaf extract under in vitro condition. The leaf extract was tested on various Gram-positive and Gram-negative bacteria to evaluate the inhibition pattern using disc diffusion assay, minimal inhibitory concentration (MIC) and minimal bactericidal concentration (MBC) technique. Disk diffusion assay showed that $S$. aureus, $S$. epidermidis, $S$. saprophyticus, $B$. cereus and $B$. subtilis were susceptible to the extract while $K$. pneumonia, P. aeruginosa, S. typhi, A. baumannii and $E$. coli were resistant. The lowest MIC values were $6.25 \mathrm{mg} / \mathrm{mL}, 12.5 \mathrm{mg} / \mathrm{mL}$ for $S$. aureus and $B$. subtilis respectively, at $24 \mathrm{~h}$ and $48 \mathrm{~h}$ of incubation period. The MBC value for $S$. aureus, B. subtilis and $B$. cereus showed no different, within $24 \mathrm{~h}$ and $48 \mathrm{~h}$, however the other values had raised. The plant has potential to be commercialized in pharmaceutical and other industries
\end{abstract}

Keywords: Alstonia angustifolia leaf, Antibacterial, Disc diffusion, MIC, MBC.

Accepted on August 07, 2018

\section{Introduction}

Plants had yield abundant range of bioactive compounds and used as reference to produce different types of medicines. It has been used for medicinal purposes in which the ethno botanical traditionally studied either using the whole plant or their parts to relieve pains of diabetes until to cancer therapy [1]. World Health Organization has estimated that about $80 \%$ of people on earth rely chiefly on traditional medicines for their primary health care needs.

In the late $19^{\text {th }}$ century, the discovery of infectious agents, which is bacteria, had trigger researchers to formulate appropriate preventative and therapeutic regimens; however, successful treatment was achieved along with discovery and introduction of antibiotics half a century later. Introduction of antibiotics into world communities have greater impact in aspect of human population as it can reduce morbidity and mortality. Regrettably, intolerance of patients to antibiotic has been led to the rapid appearance of resistant strains [2].

Antibiotic resistance has become major problems in medication of bacterial infection since resistant gene had been developed to restraint the effectiveness of one or more antibiotics which then, give dangerous signal in both developing and developed countries [3]. Therefore, vigorous study on the antibacterial activity of local medicinal plants should be performed to accommodate the production of alternative and natural-based antibacterial regimens, which are non-toxic and cause no or less side effects [4].

Alstonia angustifolia called as Pokok Pulai (locally) is a terrestrial plant that is usually found in Peninsular Malaysia, Singapore, Sumatra, Bangka and Borneo and belongs to genus Alstonia.

Prominent features of this plant are smooth outer bark, yellowish inner bark, no latex, whorls leaves, up to $45 \mathrm{~m}$ tall in size and small or steep buttresses with a diameter up to $70 \mathrm{~cm}$ [5]. It is rich in biologically active alkaloids that act as antimalarial agents to treat malaria disease, which is caused by Plasmodium falciparum [6]. It has also shown the cytotoxic activity against several human cancer cell lines [7] and has been found to assist in the fibrinolysis process by inhibiting the enzymes carboxypeptidase U (CPU) [8].

In Malays culture, remittent fever was treated by rubbed the $A$. angustifolia's leaves on the spleen areas [9]. Here, we evaluate the potential of Alstonia angustifolia leaf extract for antibacterial activity against important human pathogenic bacteria. 


\section{Materials and Methods}

\section{Plant specimen and preparation of extract}

Fresh A. angustifolia leaf was collected from Herbarium of Rimba Ilmu, Institute of Science Biology, University of Malaya, and Kuala Lumpur. The leaf was washed using distilled water and also was dried in oven at $50^{\circ} \mathrm{C}$ for $5 \mathrm{~d}$. The dried leaf was grinded using electrical blender. Hundred grams of the powdered leaf was soaked in $500 \mathrm{~mL}$ of $95 \%$ ethanol in conical flask for $3 \mathrm{~d}$. After $3 \mathrm{~d}$ the mixture were filtered using a fine muslin cloth followed by filter paper (Whatman No. 1). The filtrates were evaporated under reduced pressure in Eyela rotary evaporator. The ready crude extract was kept in $-20^{\circ} \mathrm{C}$ freeze until use.

\section{Antimicrobial susceptibility testing using the disk diffusion assay}

The Kirby-Bauer disc diffusion assay were carried out based on recommendations given by the Clinical Laboratory Standard Institute (CLSI) [10,11].

Preparation of microorganisms: 11 different species of bacteria were used in this study includes Staphylococcus aureus ATCC 25923 reference strain, Staphylococcus epidermidis ATCC 12228 reference strain, Staphylococcus saprophyticus ATCC 15305 reference strain, Escherichia coli ATCC 4157 reference strain, Klebsiella pneumonia ATCC 4352 reference strain, Pseudomonas aeruginosa ATCC 9027 reference strain, Salmonella typhi, Acinetobacter baumannii, ATCC 19606 reference strain Bacillus cereus ATCC 11778 reference strain and Bacillus subtilis ATCC 6633 reference strain. All bacteria were cultured and sub cultured again for purity on Columbia horse blood agar plates. The bacteria isolates were then maintained in Brain Heart Infusion (BHI) agar slants at $4^{\circ} \mathrm{C}$.

Preparation of discs: Stock solution of each leaf extract was prepared by dissolving $200 \mathrm{mg}$ of extract with $1 \mathrm{~mL}$ of absolute ethanol to produce final concentration of $200 \mathrm{mg} / \mathrm{mL}$. The stock solution was then diluted to concentration of 150 , 100 and $50 \mathrm{mg} / \mathrm{mL}$ of extract. $20 \mu \mathrm{l}$ of each dilution from extract were impregnated into $6 \mathrm{~mm}$ in diameter sterile, blank discs. The discs were prepared by punching Whatman No. 1 filter paper with a punch hole and then were autoclaved at $121^{\circ} \mathrm{C}$ for $20 \mathrm{~min} .5 \mu \mathrm{l}$ of extract was spotted alternately on both sides of the discs and was waited to dry before the next 5 $\mu l$ were spotted to ensure precise impregnation. Ethanol-loaded discs were then used as negative control. All discs were ensured to be fully dried before being applied on the bacterial lawn. The positive controls are Gentamicin antibiotic disc (10 $\mu \mathrm{g}$; Oxoid, UK) for $S$. aureus, $S$. saprophyticus, $S$. epidermidis, B. subtilis and B. cereus; Cephalexin antibiotic disc for $\mathrm{K}$. pnemoniae; Ticarcillin antibiotic disc for $P$. aeruginosa; Chloramphenicol antibiotic disc for $S$. typhi; Amikacin antibiotic disc for A. baumannii; Ampicillin antibiotic disc for E. coli.
Preparation of bacterial inoculums: Single colony from overnight growth on blood agar was suspended in BHI broth and incubated until visibly turbid. Their turbidity was adjusted with spectrophotometer to within an absorbance range of 0.8 to 0.13 at $625 \mathrm{~nm}$ with sterile broth, which equivalent to a 0.5 McFarland standard with a cell count of approximately $1.5 \times$ $10^{8} \mathrm{CFU} / \mathrm{mL}$ [11]. The inoculums were used within $15 \mathrm{~min}$ of standardization as delays may change the inoculums size.

Inoculation procedure: The standardized bacterial inoculums were streaked over the entire surface of $90 \mathrm{~mm}$ Mueller-Hinton agar plate with sterile cotton swab three times, rotating the agar plate about 60 degree each time to ensure that the entire agar surface was covered with the inoculums. The inoculated plates were left with the lids ajar to allow excess moisture to dry for several minutes. The antibiotic discs were applied to the agar using sterile forceps and were pressed gently to ensure uniform contact. The disc were placed 6 discs per plate (positive and negative control disc included) equidistantly to avoid the overlapping of zones of inhibition. The plates were incubated in inverted position at $37^{\circ} \mathrm{C}$ overnight. Zones of inhibition were observed visually the next day. If present, their diameters were measured to the nearest whole millimetre with a ruler against a dark, non-reflective background. The assay was carried out in triplicates and the mean diameters of zone were calculated.

\section{Minimum inhibitory concentration (MIC)}

Plates showing zones of inhibition from the disc diffusion assay were further tested to determine MIC values by broth macro-dilution method as according to recommendations by CLSI $[10,11]$.

Preparation of extract dilution: For ethanolic extract, 400 $\mathrm{mg}$ of extract was dissolved in $2 \mathrm{~mL}$ of sterile Mueller-Hinton broth (MHB) rather than the original solvent to obtain final concentration of $200 \mathrm{mg} / \mathrm{mL}$. The stock solutions prepared were serially diluted with sterile MHB to give concentrations of $100,50,25,12.5,6.25,3.125,1.563,0.781,0.391$ and 0.195 $\mathrm{mg} / \mathrm{mL}$. The concentrations were prepared to a volume of 0.5 $\mathrm{mL}$ in separate micro-centrifuge tubes (Eppendorf) at double the intended concentration so that addition of equal volumes of bacterial inoculums in later steps will result in the desired final concentration in each tube.

Inoculation procedure: Similar to disc diffusion assay, bacterial inoculums were prepared with Mueller-Hinton broth and standardized to a 0.5 MacFarland standard $\left(1.5 \times 10^{8} \mathrm{CFU} /\right.$ $\mathrm{mL})$. The suspension was diluted 1:100 with sterile broth to obtain a cell count of approximately $10^{6} \mathrm{CFU} / \mathrm{mL}$. Then 0.5 $\mathrm{mL}$ of standardized bacterial suspension was added to the tubes containing the previously prepared $0.5 \mathrm{~mL}$ of diluted extract, thus resulting in a recommended final cell count of about $5 \times$ $10^{5} \mathrm{CFU} / \mathrm{mL}$. A tube containing inoculated broth and extracts solvent (sterile MHB) but without the leaf extracts was served as the positive control. A tube containing broth alone (noninoculated) and extracts solvent served as the negative control. All tubes were incubated overnight at $37^{\circ} \mathrm{C}$. 
Determination of MIC values: The turbidity of the solution in each tube was observed the next day for indication of bacterial growth. The lowest concentration of extract dilution showing no visible growth (clear) was recorded as the MIC value. The tubes were further incubated for another $24 \mathrm{~h}$ and were observed after $48 \mathrm{~h}$ incubation for the absence or growth of bacteria (cloudy). The MIC value after 48 hours was recorded. MIC is defined as the lowest concentration where no visible turbidity is observed in the test tube (Figure 1).

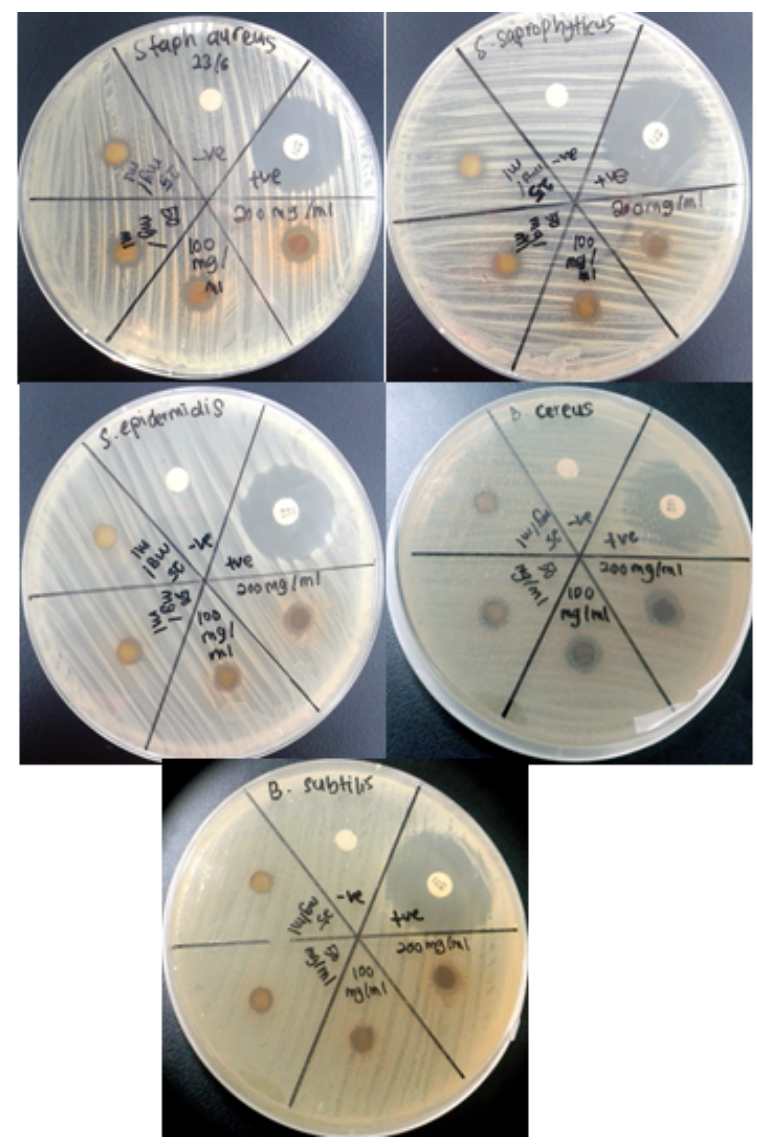

Figure 1. Clear and measurable zones of inhibitions. Inhibitions of bacterial growth by A. angustifolia leaf extract. Negative control is vaporized ethanol, Positive control is antibiotic disc; concentration of extract is $50 \mathrm{mg} / \mathrm{mL}, 100 \mathrm{mg} / \mathrm{mL}, 150 \mathrm{mg} / \mathrm{mL}, 200 \mathrm{mg} / \mathrm{mL}$.

\section{Minimum bactericidal concentration (MBC)}

The MBC is defined as the lowest concentration where no bacterial growth is observed (bactericidal concentration). This was determined from the broth dilution resulting from the MIC tubes by sub culturing to fresh agar plate. In this technique, the contents of the test tubes resulting from MIC was streaked using a sterile wire loop on agar plate free of bacteria and incubated at $37^{\circ} \mathrm{C}$ for $24 \mathrm{~h}$ and $48 \mathrm{~h}$. The lowest concentration of the extract which showed no bacterial growth was noted and recorded as the $\mathrm{MBC}$.

\section{Results}

\section{Antimicrobial susceptibility testing using disk diffusion assay}

The assay was carried out using both selected Gram positive and Gram negative bacteria. From the results of the disc diffusion assay, the leaf extract was found to possess antimicrobial properties against almost all the tested Gram positive bacteria. The diameter of clear zones of inhibition was measured against a dark and non-reflective background. However, all the tested Gram negative bacteria in this experiment were resistant towards the extract. All negative control showed no zones of inhibition (Figure 2).

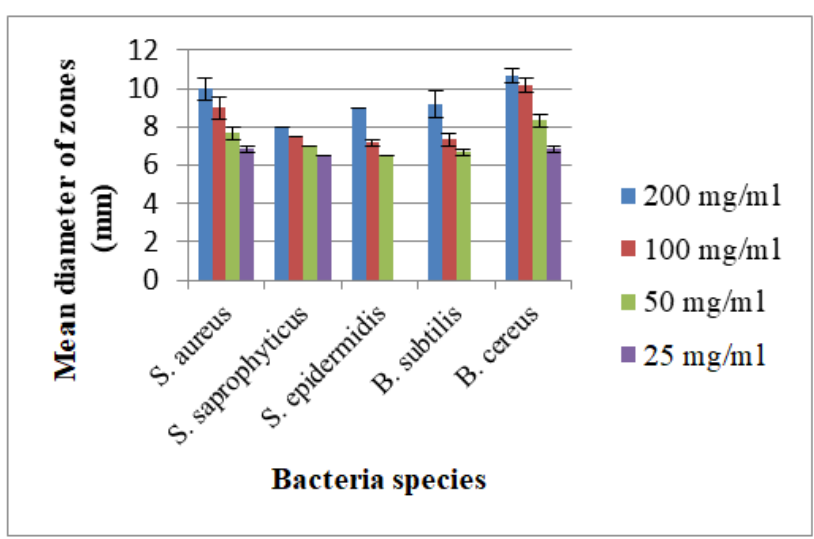

Figure 2. Mean diameter of zone of inhibitions (include $6 \mathrm{~mm}$ of diameter of disc) of leaf extract of Alstonia angustifolia at given concentrations. The value is expressed as the mean \pm S.E.M. of an experiment performed in triplicates.

\section{Minimum inhibitory concentration (MIC)}

The tested bacterial strains that are shown clearly measureable zones of inhibitions to leaf extract of $A$. angustifolia were further tested to determine their MIC values. The bacterial strains tested were $S$. aureus, $S$. epidermidis, $S$. saprophyticus, B. cereus, and B. subtilis. All MIC values obtained were presented in Tables 1 and 2 .

Table 1. Minimum inhibitory concentration (MIC) values of A. angustifolia leaf extract against susceptible bacterial strains.

\begin{tabular}{lll}
\hline & \multicolumn{2}{l}{ MIC value $(\mathbf{m g} / \mathbf{m L})$} \\
\cline { 2 - 3 } & $\mathbf{2 4 ~ \mathbf { ~ }}$ & $\mathbf{4 8 ~ h}$ \\
\hline S. aureus & $1.56 \pm 0$ & $6.25 \pm 0$ \\
\hline S. saprophyticus & $100.00 \pm 0$ & $200.00 \pm 0$ \\
\hline S. epidermidis & $12.50 \pm 0$ & $25.00 \pm 0$ \\
\hline B. subtilis & $12.50 \pm 0$ & $12.50 \pm 0$ \\
\hline B. cereus & $25.00 \pm 0$ & $25.00 \pm 0$ \\
\hline
\end{tabular}

Table 2. Minimum bactericidal concentration (MBC) values of $A$. angustifolia leaf extract against susceptible bacterial strains. 


\begin{tabular}{|c|c|c|}
\hline & \multicolumn{2}{|c|}{ MBC value $(\mathrm{mg} / \mathrm{mL})$} \\
\hline & $24 \mathrm{~h}$ & $48 \mathrm{~h}$ \\
\hline S. aureus & $6.25 \pm 0$ & $6.25 \pm 0$ \\
\hline S. saprophyticus & $200.00 \pm 0$ & $200.00 \pm 0$ \\
\hline
\end{tabular}

\begin{tabular}{lcc}
\hline S. epidermidis & $12.50 \pm 0$ & $12.50 \pm 0$ \\
\hline B. subtilis & $12.50 \pm 0$ & $12.50 \pm 0$ \\
\hline B. cereus & $25.00 \pm 0$ & $25.00 \pm 0$ \\
\hline
\end{tabular}
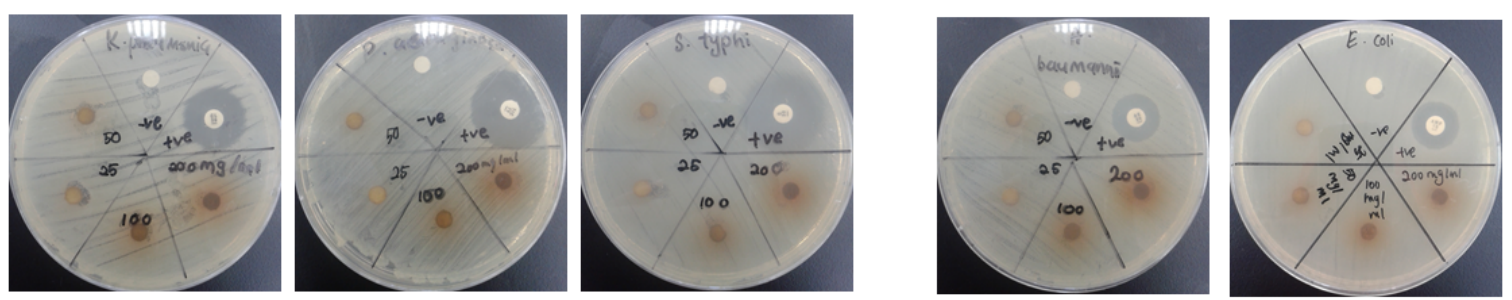

Figure 3. Zone of inhibitions was not seen (negative results). Negative control is vaporized ethanol, Positive control is antibiotic disc; concentration of extract is $50 \mathrm{mg} / \mathrm{mL}, 100 \mathrm{mg} / \mathrm{mL}, 150 \mathrm{mg} / \mathrm{mL}, 200 \mathrm{mg} / \mathrm{mL}$.

\section{Discussion}

Plant based antibacterial compounds have enormous therapeutic potential as they can serve the treatment without any side effects that are often related with synthetic and semisynthetic anti-bacterials.

From the results of the disc diffusion screening, leaf extract of $A$. angustifolia was found to possess antibacterial properties against $S$. aureus, S. epidermidis, S. saprophyticus, B. cereus and $B$. subtilis, reflected from the zone of inhibition. Therefore, this might indicate that the leaf extract act specifically against Gram positive Staphylococcal and Bacillus cell wall that correlated with the study by Sudjana et al. [12]. However, in this experiment, it was showed that the extract does not possess antibacterial properties against Gram negative bacterial strains as there is no significant and measureable zone of inhibition seen. These findings may due to the characteristics of Gram negative bacteria that have extra resistance against antibacterial agents resulted from outer membrane that present in their cell wall. The outer membranes that compose lipopolysaccharides prevent the antibacterial agents such this extract to pass through it [13]. Furthermore, bacterial resistance towards antibiotics can occur via intrinsic and acquired mechanisms. In the intrinsic mechanism, resistance is activated through the action of genes in bacterial chromosome and many MDR efflux systems. While acquired mechanism happens when there are mutations on the antibiotic-targeted genes [14].

The study on the antibacterial activity of $A$. angustifolia leaf extract has yet to be carried out; hence we compared our findings with the $A$. macrophylla which is the same genus of $A$. angustifolia. Phytochemical analysis showed that crude extract from leaf and stem bark of $A$. macrophylla contains tannins, saponins, flavonoids, sterols, reducing sugars and triterpene. The crude extract (methanol extraction), methanol-aqueous extract and n-butanol extract have the potential to inhibit the growth of $S$. aureus, S. saprophyticus, S. faecalis, P. mirabilis, E. coli, T. rubrum, T. mentagrophytes and M. gypseum. In addition, the tested extract was resistant to the strains of $P$. aeruginosa, Klebsiella $s p$. and $V$. cholera [15]. Our study showed that the ethanolic extracts from the leaf extract of $A$. angustifolia had marked antibacterial effect against $S$. aureus, S. saprophyticus, S. epidermidis, B. subtilis and B. cereus and resistant to $P$. aeruginosa, $K$. pneumonia, $S$. typhi, $A$. baumannii and E. coli.

MIC test was performed for more accurate quantitative determination of antimicrobial strength of the extract as compared to the disc diffusion assay. The lower the MIC value, the lower the concentration needed for the extract to completely inhibit the bacterial growth which means the stronger the antimicrobial strength [16]. The MIC concentration ranged from $6.25 \mathrm{mg} / \mathrm{mL}$ to $200 \mathrm{mg} / \mathrm{mL}$. The lowest MIC values recorded were against $S$. aureus strain $(6.25$ $\mathrm{mg} / \mathrm{mL}$ ), followed by $S$. saprophyticus and $S$. epidermidis $(12.50 \mathrm{mg} / \mathrm{mL})$. The lowest MBC value was $6.25 \mathrm{mg} / \mathrm{mL}$ to kill $S$. aureus completely. The MIC values of $S$. epidermidis, $B$. subtilis and $B$. cereus showed same concentration in both incubation periods while MIC values for $S$. aureus and $S$. saprophyticus slightly difference between the both incubation periods. MBC values for all tested bacteria showed same concentration in both incubation periods.

This suggests that constant concentrations of $A$. angustifolia leaf extract are needed to inhibit visible growth of $S$. epidermidis, B. subtilis and B. cereus bacteria species and completely kill the bacteria. Our findings showed that bactericidal effect of this plant leaf extract require higher concentration compare to inhibitory effect against $S$. aureus and $S$. saprophyticus. However, equal concentration of bactericidal and inhibitory effect is suggested to react against S. epidermidis, B. subtilis and B. cereus.

\section{Conclusion}

This present study demonstrated that the leaf extract of $A$. angustifolia did possess the antibacterial activity against $S$. aureus, S. epidermidis, $S$. saprophyticus, B. subtilis and $B$. cereus. It showed that the extract had the highest activity against $S$. aureus species. However, further studies such as high performance liquid chromatography is recommended to find the active compounds that responsible in the antibacterial actions, therefore the applications can be widening. 


\section{Acknowledgement}

The authors are highly thankful to the Microbiology Laboratory, Faculty of Health Sciences, University Teknologi Mara (UiTM) for providing the facilities and specialties for this research work. This study was supported by Ministry of Higher Education (MOHE) of Malaysia under Research Acculturation Grant Scheme (RAGS/1/2014/SKK01/ $\mathrm{UITM} / / 6)$.

\section{References}

1. Misra CS, Pratyush K, Sagadevan LDM, James J, Veettil AKT, Thankamani V. A comparative study on phytochemical screening and antibacterial activity of roots of Alstonia scholaris with the roots leaves and stem bark. Int J Res Phytochem Pharmacol 2011; 2: 77-82.

2. Julian D, Dorothy D. Origins and evolution of antibiotic resistance. american society for microbiology. Microbiol Mol Biol Rev 2010; 3417-3433.

3. Projan SJ, Bradford PA. Late state antibacterial drugs in the clinical pipeline. Curr Opin Microbiol 2007; 10: 441-446.

4. Ongsakul M, Jindarat A, Rojanaworarit C. Antibacterial effect of crude alcoholic and aqueous extracts of six medicinal plants against Staphylococcus Aureus and Escherichia Coli. J Health Res 2009; 23: 153-156.

5. Teo SP. Alstonia angustifolia Wallich ex A. DC. Plant resources of South East Asia: medicinal and poisonous plants. Bachuys Publisher, Leiden, The Netherlands 2001.

6. Kam TS. Alkaloids from Malaysian flora, in alkaloids. Chemical and Biological Perspectives. Pergamon, Amsterdam 1999.

7. Kam TS, Tan SJ, NG SW, Komiyama K. Bibleiophylline, an unprecedented cytotoxic bisindole alkaloid constituted from the bridging of two indole moieties by an aromatic spacer unit. Organic Lett 2008; 10: 3749-3752.

8. Carroll AR, Hyde E, Smith J, Quinn RJ, Guymer G, Forster PI. Actinophyllic acid, a potent indole alkaloid inhibitorof the coupled enzyme assay carboxypeptidase $\mathrm{u} /$ hippuricase from the leaves of Alstonia actinophylla (Apocynaceae). J Organic Chem 2005; 70: 1096-1099.
9. Shin-Jowl T, Yeun-Mun C, Noel FT, Ward TR, Kanki K, Kam TS. Unusual indole alkaloid-pyrrole,-pyrone, and carbamic acid adducts from Alstonia angustifolia. Tetrahedron 2010; 66: 7799-7806.

10. Hindler JF, Jorgensen JH. Antimicrobial susceptibility testing: Procedures in antimicrobial susceptibility testing. Textbook of Diagnostic Microbiology (3rd ed). Saunders Elsevier, China 2007.

11. Jorgesen JH, Turnidge JD. Susceptibility test methods: Dilution and disk diffusion methods. Manual of Clinical Microbiology (9th ed). ASM Press, District of Columbia, Washington 2007.

12. Sudjana AN, Thuam DT, Bighelli A, Castola V, Muselli A. Baeckea frustescens leaf oil from Vietnam: Composition and chemical variability. Flavour Fragrance J 2004; 19: 217-222.

13. Sheldon A. Antibiotic mechanisms of action and resistance. Textbook of Diagnostic Microbiology (3rd ed). Saunders Elsevier, China 2007.

14. Fadli M, Chevalier J, Hassani L, Mezrioui NE, Pagès JM. Natural extracts stimulate membrane-associated mechanisms of resistance in Gram-negative bacteria. Lett Appl Microbiol 2014; 58: 472-477.

15. Chattopadyay D, Maiti K, Kundu AP, Chakraborty MS, Bhadra R, Mandal SC, Mandal AB. Antimicrobial activity of Alstonia macrophylla: A folklore of Bay islands. J Ethnopharmacol 2001; 77: 49-55.

16. Upadhyay RK, Dwivedi P, Ahmad S. Screening of antibacterial activity of six plant essential oils against pathogenic bacterial strains. Asian J Med Sci 2010; 2: 152-158.

\section{*Correspondence to}

Nurhidayah Ab Rahim

Faculty of Health Sciences

University Technology MARA

Pulau Pinang Branch (Bertam Campus)

Malaysia 